ఠ

\title{
Endophthalmitis: Pathogenesis, clinical presentation, management, and perspectives
}

REVIEW

This article was published in the following Dove Press journal:

Clinical Ophthalmology

4 March 2010

Number of times this article has been viewed

\author{
M Kernt \\ A Kampik \\ Department of Ophthalmology, \\ Ludwig Maximilian University, Munich, \\ Germany
}

\begin{abstract}
Endophthalmitis is a rare but sight-threatening complication that can occur after ocular surgery or trauma or as a consequence of systemic infection. To optimize visual outcome, early diagnosis and treatment are essential. Over recent decades, advances in hygienic standards, improved microbiologic and surgical techniques, development of powerful antimicrobial drugs, and the introduction of intravitreal antibiotic therapy have led to a decreased incidence and improved management of endophthalmitis. However, endophthalmitis still represents a serious clinical problem. This review focuses on current principles and techniques for evaluation and treatment of endophthalmitis. In addition, it addresses recent developments regarding antimicrobial treatment and prophylaxis of infectious endophthalmitis.

Keywords: endophthalmitis, intravitreal, antibiotics, victrectomy, moxifloxacin, voriconazole, caspofungin
\end{abstract}

\section{Introduction}

Endophthalmitis is one of the most devastating diagnoses in ophthalmology. It is a serious intraocular inflammatory disorder affecting the vitreous cavity that can result from exogenous or endogenous spread of infecting organisms into the eye. ${ }^{1}$ With any breaching of the ocular bulbus, the potential exists for introducing an infectious inoculum large enough to cause an intraocular infection. This is most commonly seen after intraocular surgery but can also occur as a complication of penetrating ocular trauma or from the adjacent periocular tissues.

Endogenous endophthalmitis is less common and occurs secondary to hematogenous dissemination and spread from a distant infective source in the body. In patients with endogenous endophthalmitis, predisposing risk factors usually exist. ${ }^{2-6}$

In most cases, independent of its origin, the presentation of endophthalmitis consists of reduced or blurred vision, red eye, pain, and lid swelling. ${ }^{3,5,7,8}$ Progressive vitritis is one of the key findings in any form of endophthalmitis, and in nearly $75 \%$ of patients a hypopyon can be seen at the time of presentation ${ }^{1}$ (see Figure 1). Progression of the disease may lead to panophthalmitis, corneal infiltration, and perforation, affection of orbital stuctures, and phthisis bulbi.

In general, the incidence of endophthalmitis has decreased in recent decades ${ }^{9}$ and, fortunately, endophthalmitis is rare. ${ }^{7,9,10}$ Nonetheless, its evident severity and indistinct prognosis require timely and effective treatment to provide satisfactory visual results.
Department of Ophthalmology, Ludwig

Maximilian University, Mathilden St. 8,

80336 Munich, Germany

Tel +498951603811

Fax +498951605160

Email marcus.kernt@med.uni-muenchen.de 


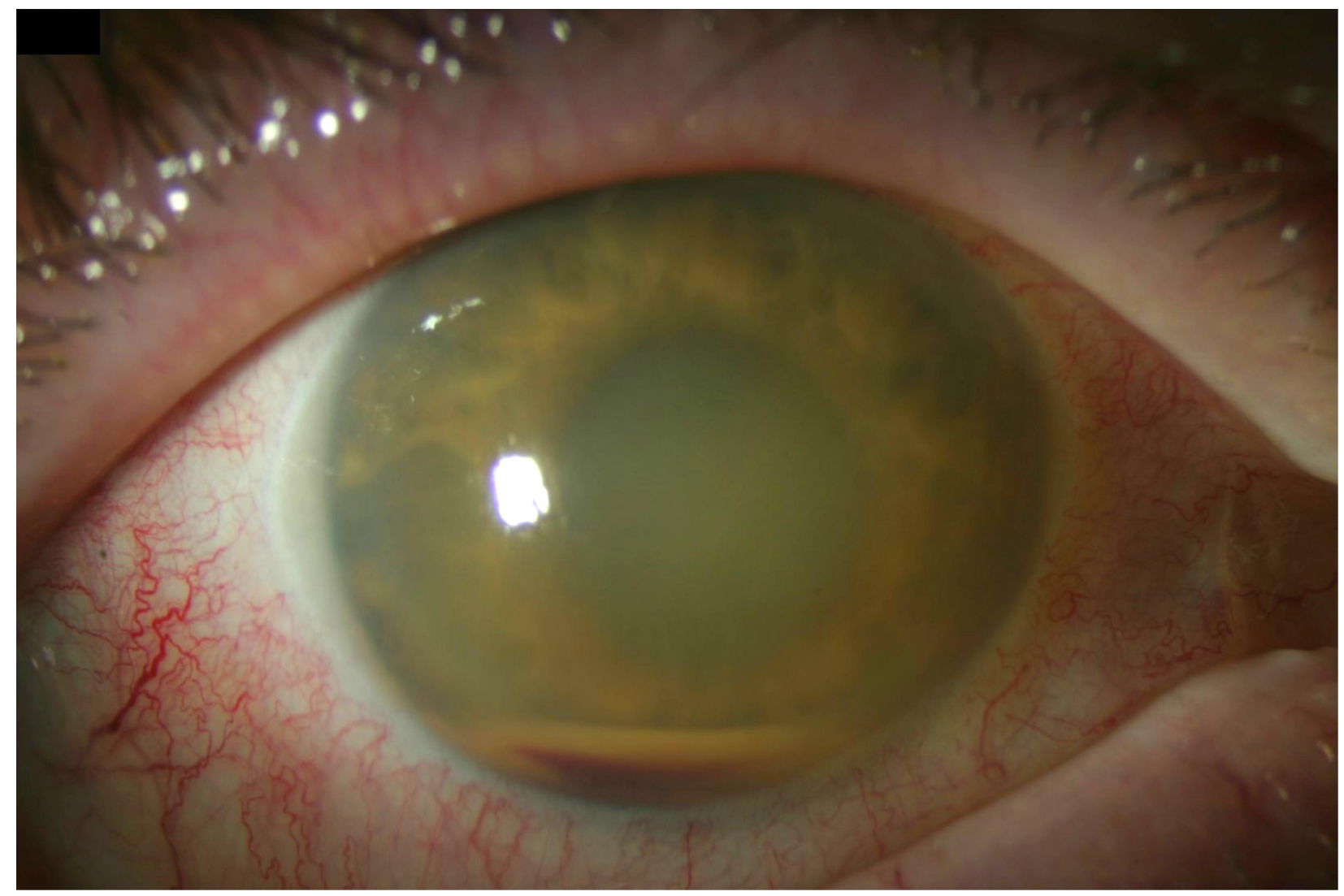

Figure I Anterior chamber inflammation, mild corneal edema, and hypopyon in bacterial endophthalmitis.

\section{Pathogenesis and clinical presentation}

\section{Exogenous endophthalmitis}

Postoperative endophthalmitis

Endophthalmitis after ocular surgery is the most common form of the condition. Cataract surgery is by far the most frequently performed intraocular surgery. ${ }^{11}$ Approximately $90 \%$ of postoperative endophthalmitis cases develop after this procedure ${ }^{7,9,10}$ with an incidence following such surgery ranging from $0.08 \%$ to $0.7 \% .^{10,12-15} \mathrm{~A}$ recently published meta-analysis indicates that the endophthalmitis rate seems to have increased during the last two decades. ${ }^{16}$ According to these data, the rate of endophthalmitis following cataract surgery was about $0.09 \%$ during the 1990 s and $0.27 \%$ in $2000 .{ }^{16}$ Greater use of clear corneal incision has been debated as a potential reason for this. Experimental data indicate that with this technique wound architecture seems to be less stable, thus allowing fluctuations in the intraocular pressure and potentially easier entry of bacteria through a less completely sealed wound. Some studies found a threeto four-fold risk for endophthalmitis after clear cornea cataract surgery compared with scleral tunnel incisions. ${ }^{17,18}$
In contrast, Lalwani et al reviewed 73 endophthalmitis cases after clear cornea cataract surgery and compared them with the data from the Endophthalmitis Vitrectomy Study (EVS), in which scleral tunnel and clear cornea incisions were used. They found that time to endophthalmitis diagnosis was longer in clear cornea cataract surgery cases but clinical features, causative organisms, and visual acuity outcomes were similar to those reported in the EVS. ${ }^{19}$

Wound integrity also seems to be an important feature influencing the risk for developing endophthalmitis in pars plana vitrectomy. In general, the incidence of endophthalmitis after pars plana vitrectomy is low $(0.03 \%-0.05 \%))^{10,20}$ Nevertheless, recent data indicate that the use of sutureless small incision techniques (eg, 23- or 25-gauge incision size) is significantly associated with a higher rate of postoperative endophthalmitis than the sutured 20 -gauge technique. ${ }^{21}$

However, endophthalmitis can also complicate other ocular surgeries and procedures such as intravitreal injections. ${ }^{22,23}$ Some data suggest that penetrating keratoplasty, trabeculectomy, and glaucoma drainage device implantation have a higher risk of being complicated by endophthalmitis than cataract surgery. ${ }^{24-26}$ Regarding glaucoma filtering surgery, 
endophthalmitis is reported to occur after $0.2 \%-9.6 \%$ of trabeculectomies, ${ }^{24,27-32}$ and its incidence seems to increase with the rising use of antifibrotic agents, such as mitomycinC or 5-fluorouracil. ${ }^{27-29,32,33}$ Endophthalmitis rarely occurs after external ocular surgeries including scleral buckling, pterygium excision, removal of corneal sutures, and strabological interventions. ${ }^{34-38}$

In general, secondary intraocular lens placement seems to be associated with the highest risk for developing endophthalmitis $(0.2 \%-0.37 \%)$ and pars plana vitrectomy with the lowest $(0.03 \%-0.05 \%) .{ }^{10,20}$

Preoperative risk factors include eyelid abnormalities, blepharitis, conjunctivitis, cannuliculitis, lacrimal duct obstructions, contact lens wear, and ocular prosthesis in the fellow orbit. ${ }^{39-42}$

The ocular surface and the adnexa are considered the primary sources of infection in postoperative endophthalmitis. ${ }^{41}$ However, contaminated agents or surgical equipment used perioperatively may also be a source of infection. ${ }^{43-45}$ In addition, perioperative variations seem to have some impact on postoperative endophthalmitis rate; different intraocular lens (IOL) materials potentially act as vectors for bacterial spread into the eye ${ }^{11,46,47}$ and viscoelastic substances, such as sodium hyaluronate, or hydroxypropylmethylcellulose may facilitate transmission of bacteria to the eye. ${ }^{48,49}$

Knowledge about the cause of endophthalmitis is essential because the spectrum of organisms may change, warranting different therapeutic approaches. Bacteria infections are the most common cause of postoperative endophthalmitis, and Gram-positive isolates account for most cases. ${ }^{7,10,15,50}$ Fungal infections may also occur, particularly in association with the use of contaminated ocular irrigation fluids. ${ }^{43,51}$

Postoperative endophthalmitis can be either sterile or infectious. In the EVS, only $69.3 \%$ of cases met the criteria for laboratory-confirmed infection. ${ }^{7}$ The reasons that more than $30 \%$ of cases failed to obtain positive results from culture vary and include low microbial counts, spontaneously sterilizing during the ocular inflammatory response of certain strains (eg, Staphylococcus epidermidis), or even noninfectious inflammations. ${ }^{7,10,15,50,52}$

In addition, the etiology of endophthalmitis might differ depending on the location in the world where the disease occurs. Whereas the microbiologic spectrum in Europe or in the US seems to be generally comparable, ${ }^{7,46}$ it might be very different in other parts of the world. According to the EVS, $94.2 \%$ of culture-positive endophthalmitis cases involved Gram-positive bacteria; $70 \%$ of isolates were Gram-positive, coagulase-negative staphylococci, $9.9 \%$ were Staphylococcus aureus, 9.0\% were Streptococcus species, $2.2 \%$ were Enterococcus species, and 3\% were other Gram-positive species. Gram-negative species were involved in $5.9 \%$ of cases. ${ }^{7}$ In contrast, a recent survey from India reported that Grampositive bacteria accounted for only $53 \%$ of postoperative endophthalmitis cases, but $26 \%$ were Gram-negative isolates and $17 \%$ were of fungal origin. ${ }^{53}$

The advent of new therapeutic strategies for treating age-related macular degeneration, diabetic macular edema, and uveitis has led to a dramatic increase in intravitreal drug application. The risk of endophthalmitis after intravitreal injection is of rising concern. ${ }^{23}$ Recent data, albeit limited, indicate that coagulase-negative staphylococci, as in postoperative endophthalmitis, appear to be the predominant pathogens in the development of endophthalmitis after intravitreal injection. ${ }^{23}$ Less common organisms, including Streptobacillus parasanguis, Mycobacterium chelonae, and Streptobacillus species, as well as cases of noninfectious (sterile) endophthalmitis, especially in the context of intravitreal triamcinolone acetonide injections, have been reported in the literature. $22,23,54$

The majority of patients with postoperative endophthalmitis present with an acute onset and within seven days after surgery. ${ }^{7,55}$ Chronic postoperative endophthalmitis is characterized by insidious inflammation and appears less common than the acute variety. Such cases can occur in the early postoperative period but usually manifest several weeks or month after surgery and often include less virulent bacteria and fungal pathogens.

Depending on the infecting organism, a correlation is thought to exist between clinical presentation and microbiologic spectrum. Gram-positive, coagulase-negative micrococci seem to cause less severe infections compared with more virulent Gram-negative and "other” Gram-positive organisms. ${ }^{7}$ Streptococcal endophthalmitis often results in earlier onset and notably worse outcomes than infections by staphylococcal species. Endophthalmitis cases that failed to obtain positive results from culture tended to have a later onset and a better visual outcome. ${ }^{55-59}$

More severe infections are correlated with loss of red fundus reflex, afferent papillary defect, and light perception only at the time of initial presentation. ${ }^{7}$ The presence of corneal infiltrates or cataract wound abnormalities are more strongly associated with more virulent Gram-negative and "other" Gram-positive organisms. ${ }^{7}$ In addition, when more virulent pathogens are involved, signs and symptoms of endophthalmitis might be apparent earlier. ${ }^{7}$ This is important because these cases seem to be significantly correlated with a worse visual outcome. 
Specific factors influencing bacterial adhesion, including IOL material and surface irregularities, might have a role in the development of certain forms of endophthalmitis. Sepidermidis carrying the intercellular adhesion locus might play a part in the pathogenesis of some forms of endophthalmitis. ${ }^{60,61}$

In most cases the diagnosis of endophthalmitis is made on clinical grounds. Any eye with inflammation that is out of proportion to the previous surgical trauma or greater than the predicted postoperative clinical course must be suspected as indicating postoperative endophthalmitis. If doubt cannot be erased, frequent observations should be conducted until the clinical course can be determined. Symptoms can be variable, from very little inflammation in the anterior chamber and the anterior portion of the vitreous to extremely painful panopthalmitis with no fundus view, corneal edema, or complete anterior chamber hypopyon ${ }^{7,24,50}$ (see Figure 2).

According to the EVS, hypopyon can be seen in nearly $75 \%$ of patients, whereas ocular pain, often regarded as pathognomonic for endophthalmitis, was absent in $25 \%$ of patients. ${ }^{7}$ In the European Society of Cataract and Refractive Surgeons Endophthalmitis Study (ESCRS) of prophylaxis for postoperative endophthalmitis after cataract surgery, hypopyon was present in $80 \%$ of culture-proven cases and $56 \%$ of unproven cases, resulting in an overall incidence of $72 \% .{ }^{55}$ Most common presentations include decreased vision, ocular pain and redness, corneal edema, and vitritis. In addition, retinal vasculitis, retinal hemorrhages, and posterior pole hypopyon may occur ${ }^{7,24,50}$ (see Figure 3).

\section{Posttraumatic endophthalmitis}

Endophthalmitis is an important complication of open globe injury. About $25 \%$ of endophthalmitis cases are a result of ocular trauma and these are more often associated with a poorer visual outcome than otherwise similar globe injuries. ${ }^{8}$ After posttraumatic endophthalmitis, only $22 \%$ to $42 \%$ of patients obtain a final visual acuity of $20 / 400$ or better. ${ }^{62-64}$

The risk for developing endophthalmitis after sustaining open globe injuries is estimated at about 7\%..$^{1,8,65}$ Increasing risk factors for endophthalmitis after ocular injury are dirty wound, lens capsule rupture, older age, initial presentation with a delay of more than 24 hours, and the presence of intraocular foreign bodies. ${ }^{8,66-69}$ The incidence of endophthalmitis in cases of penetrating ocular trauma has been reported to range from $3.3 \%$ to $30 \%$ and after intraocular foreign body from $1.3 \%$ to $61 \%$. $^{8,63}$

A recent study from China, including 4968 eyes with open globe injury, found an incidence of posttraumatic endophthalmitis of $11.9 \%,{ }^{70}$ which is consistent with previous published data within the range of $2.6 \%$ to $54.2 \%$. $^{70-73}$ In contrast, no evident correlation is found between the results of intraocular content culturing and development of posttraumatic endophthalmitis. Ariyasu and colleagues found that $33 \%$ of open globe injuries were culture-positive when aqueous was sampled, but none of these patients developed endophthalmitis. ${ }^{66}$ In contrast, the prevalence of culture-negative cases of posttraumatic endophthalmitis has

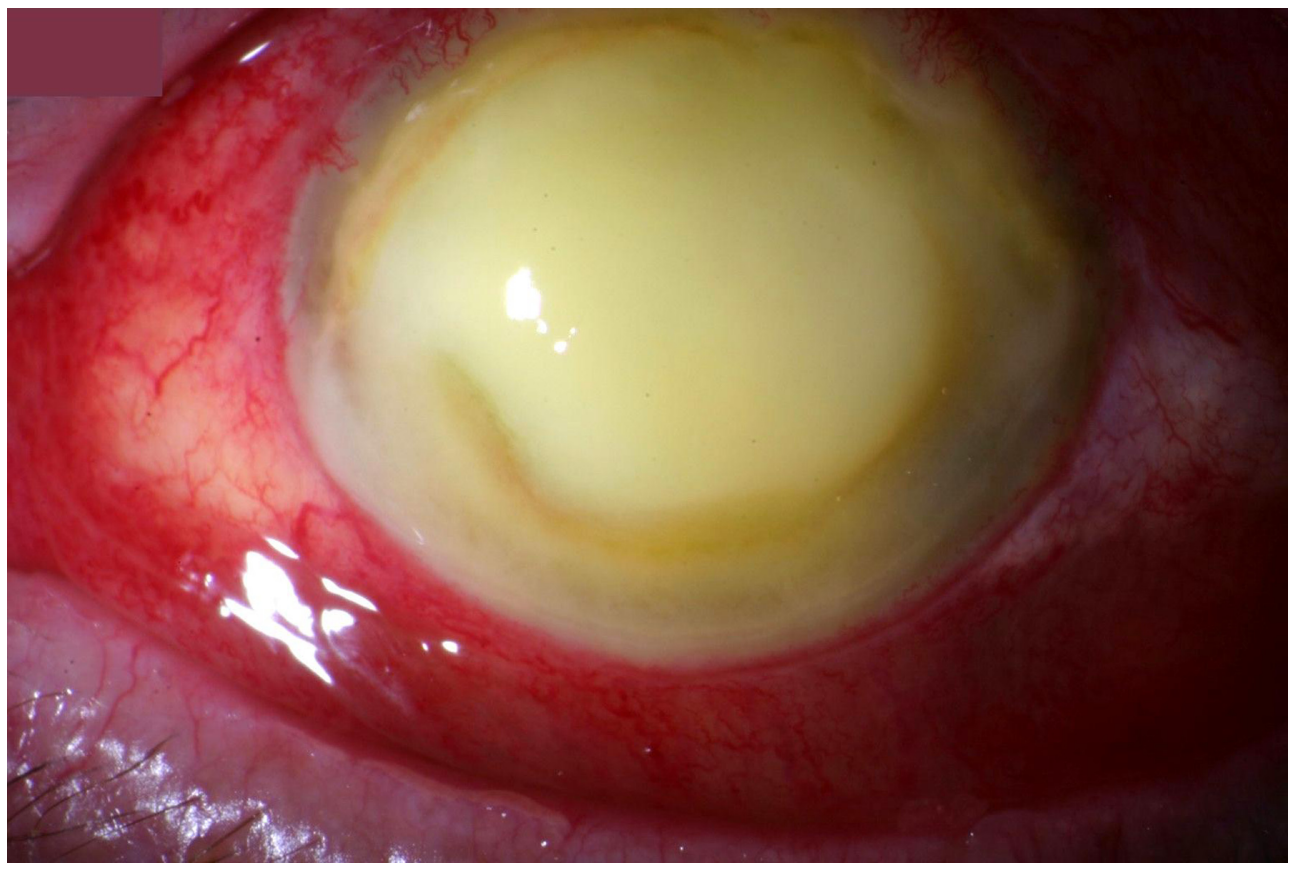

Figure 2 Leukocornea as a result of massive corneal edema and complete hypopyon in advanced Staphylococcus aureus endophthalmitis. 


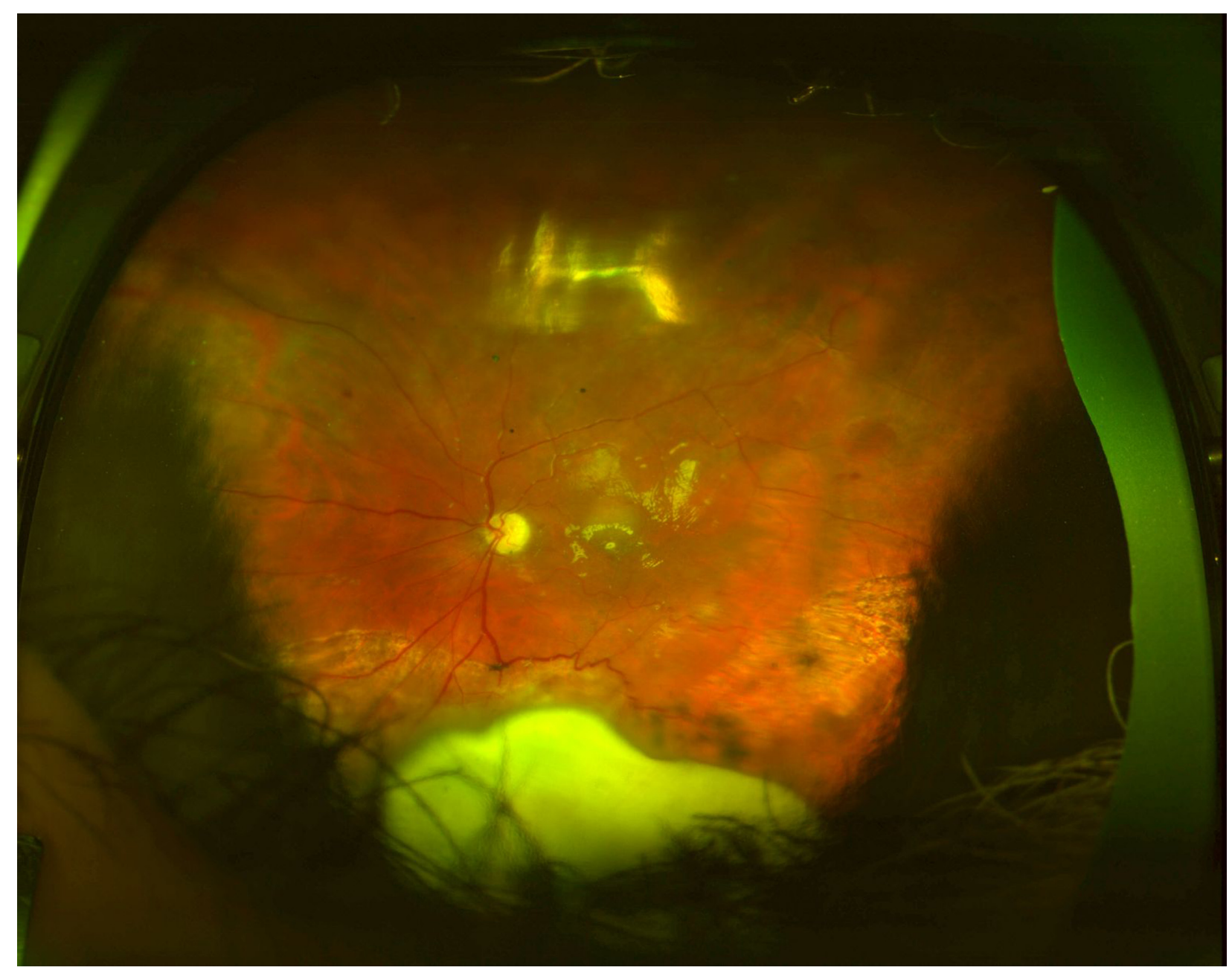

Figure 3 Posterior hypopyon in bacterial endophthalmitis imaged with Optomap widefield fundus imaging.

been reported to range from $17 \%$ to $42 \%{ }^{67,68,74-76}$ Therefore, some authors do not suggest routine culture in all cases of open globe injury. ${ }^{67}$

Bacillus and Streptococcus are common species found in penetrating trauma with an intraocular foreign body. ${ }^{68}$ This is important because Bacillus species are associated with more aggressive infection and are especially common in intraocular foreign bodies with organic composition. ${ }^{64}$ Other species isolated include S. epidermidis, Propionibacterium acnes, Pseudomonas and Streptococcus species, Gram-negative organisms, fungi, and mixed pathogens. , $^{8,470}$

Initial evaluation of posttraumatic endophthalmitis must exclude occult or retained foreign bodies. If the fundus view is inadequate, computed tomography or, in eyes with self-sealing or previously sutured wounds, ultrasound may be helpful. Magnetic resonance imaging must be avoided because a retained foreign body might be magnetic.
Posttraumatic endophthalmitis may also be a result of contagious spread from an infected corneal, scleral, or adjacent wound. ${ }^{8,68-70}$ Depending on the virulence of the infecting organism, posttraumatic endophthalmitis may occur within hours after the trauma or up to several weeks after injury. ${ }^{8,68-70}$ Signs and symptoms must be evaluated with regard to the degree of traumatic injury and include decreased vision, pain greater than expected, lid swelling, corneal ring ulcer, anterior chamber inflammation, hypopyon, vitritis, or frank purulence.

\section{Endogenous endophthalmitis}

Unlike the origin in exogenous endophthalmitis, where the pathogen enters from outside the body into the eye, in endogenous endophthalmitis the infection is secondary to hematogenous spread from a distant infective source within the body. The endogenous form of endophthalmitis accounts 
for approximately $5 \%$ to $10 \%$ of endophthalmitis cases. ${ }^{3,4,77-80}$ It occurs when microorganisms in the bloodstream get into the eye, cross the blood-retina barrier, and infect the ocular tissue. Because of the higher blood flow, choroids and ciliary body are the primary focuses of infection in the eye with secondary involvement of the retina and vitreous. ${ }^{3,5,79,81}$

Risk factors for the development of endogenous endophthalmitis are mainly related to immunosuppression or to procedures that increase the risk for blood-borne infections. Most common factors include immunosuppressive diseases, such as diabetes mellitus, HIV infection, cancer, renal failure requiring dialysis, cardiac disease, long-term use of broad-spectrum antibiotics, steroids and other immunosuppressive drugs, major surgery, especially intra-abdominal surgery, intravenous hyperalimentation, indwelling intravenous catheters, and intravenous drug abuse..$^{3,477-80}$ Liver abscesses have been reported as the most common infectious origin, ${ }^{3,82-84}$ followed by pneumonia, endocarditis, soft tissue infection, urinary tract infections, meningitis, septic arthritis, and orbital cellulitis. ${ }^{3}$

Causative organisms of endogenous endophthalmitis may be bacteria, as well as fungi, and rarely parasites. In contrast to exogenous forms of this disease, in endogenous endophthalmitis fungal pathogens play an important role. ${ }^{3,4,85}$ However, the infecting organisms vary with geographic location.

In Europe and the US, Streptococcus species, S. aureus, and other Gram-positive bacteria account for two-thirds of bacterial endogenous endophthalmitis cases and Gramnegative isolates are found in only $32 \%$ of cases. ${ }^{4,79}$ These numbers differ significantly from East Asia, where most cases of endogenous endophthalmitis are caused by Gramnegative organisms. In these areas, Klebsiella isolates count for $80 \%$ to $90 \%$ of positive cultures. ${ }^{3,83}$ This difference might be attributable to the higher incidence of cholangiohepatitis and liver abscess in East Asian people than in the Western population. ${ }^{3,82-84}$ However, during the last two decades, the number of endogenous ocular infections due to Gram-negative pathogens has dramatically increased in the Western world..$^{79}$ In contrast with its prominent role in acute postoperative endophthalmitis, S. epidermidis is only rarely found to cause endogenous endophthalmitis. ${ }^{3}$

Fungal endophthalmitis has become an increasing issue in western countries. Candida albicans followed by Aspergillus are the predominant species. ${ }^{3,85}$ Candida species are a part of the human flora where they exist as commensals on the mucosal surface of the respiratory, gastrointestinal, and female genital tracts. ${ }^{86}$ Where the immune system is compromised these organisms potentially become pathogenic. Candida species are the most common cause of nosocomial fungal infections. ${ }^{87-89}$

Candida chorioretinitis and endophthalmitis occur predominantly as a result of candidemia seeding the eye; cases in otherwise healthy individuals have rarely been reported ${ }^{90,91}$ Prospective studies demonstrated that patients with candidemia have a risk of developing endogenous fungal endophthalmitis of up to $49 \%{ }^{2,81,92,93}$ However, a recently published study demonstrated that in patients with disseminated fungal disease, Candida chorioretinitis and endophthalmitis occurred in approximately $2.5 \%$ of cases. ${ }^{94}$ These data might indicate that the current trend for prophylaxis and early treatment, as well as new drugs and treatment strategies for Candida infections, have decreased the incidence of fungal ocular complications dramatically. ${ }^{94,95}$ Other isolates commonly found in endogenous fungal endophthalmitis are Cryptococcus and Fusarium species. ${ }^{85,90}$

Clinical findings in endogenous endophthalmitis may be similar to those in infections of exogenous origin. They include decreased vision, ocular pain, conjunctiva injection, hypopyon, corneal edema, vitritis, and reduced fundus view secondary to inflammation. Especially in cases of fungal infection, a subacute onset of floaters and blurred vision may be associated with ocular discomfort and photophobia. ${ }^{94} \mathrm{In}$ Candida infections, localized fluffy creamy white retinal or subretinal nodules may be associated with vitreous haze. ${ }^{86,94}$ (see Figure 4). Early or peripheral fungal lesions may be asymptomatic, with patient referral for ocular consultation based on a positive blood culture or diagnosis of a systemic fungal infection. When more virulent pathogens are involved, widespread areas of perivascular infiltrates and hemorrhages with necrosis and retinal infarction can be seen. ${ }^{5,8,96,97}$ In panophthalmitis, the whole globe and the orbital tissue may be involved. ${ }^{5,84}$

\section{Management and perspectives}

The prognosis of endophthalmitis, whether of exogenous or endogenous origin, is often poor. In general, endophthalmitis is recognized as an ominous disease, which runs a potentially devastating course, leaving only very limited visual function in many patients. Therefore, early diagnosis and treatment with antimicrobial therapy are fundamental to optimize visual outcome. In addition, the anticipated rise in ocular surgeries, as well as growing evidence that the rates of postoperative endophthalmitis might increase, underscore the importance of identifying effective methods of prophylaxis for improving surgical safety. 


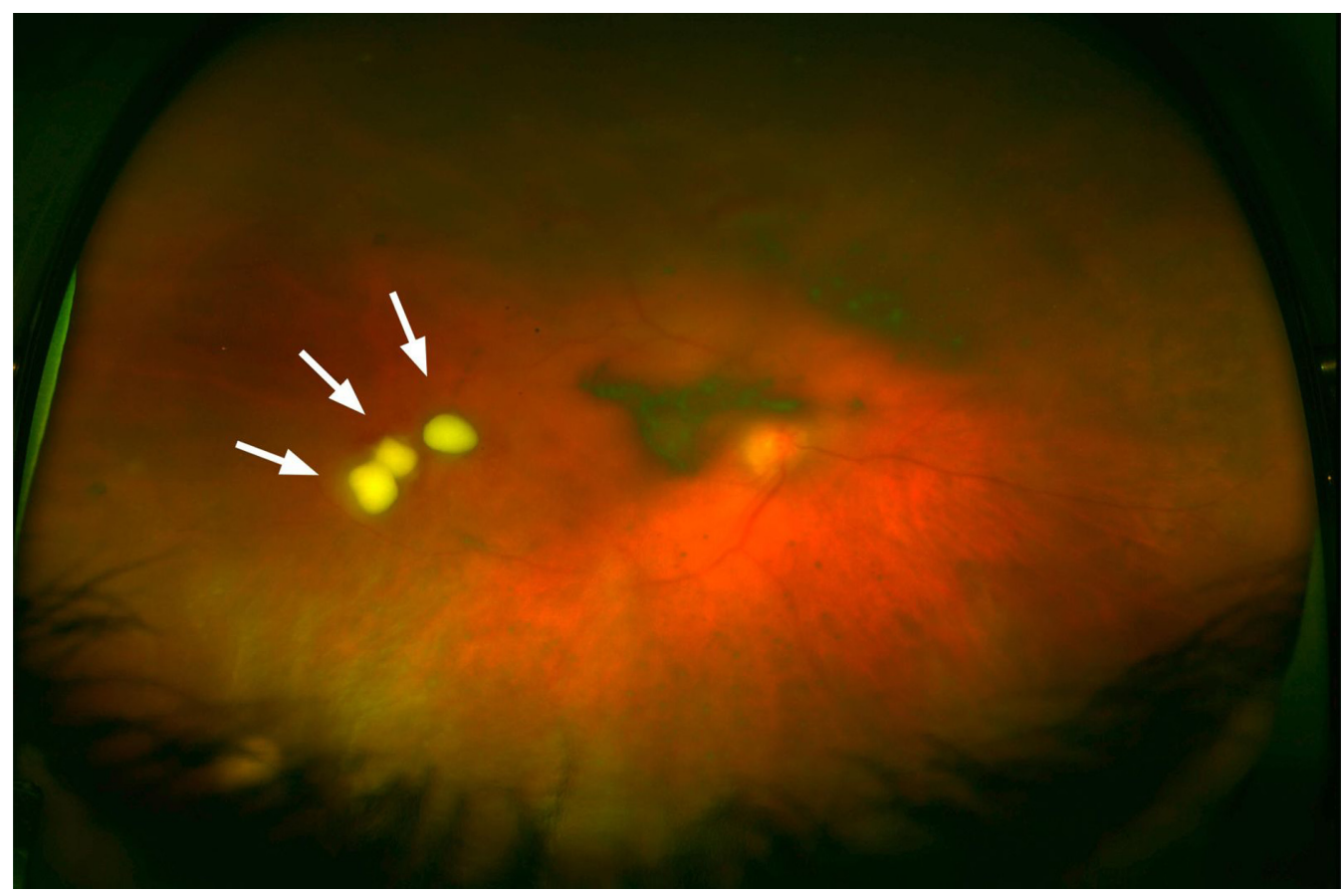

Figure 4 Localized epiretinal infiltrates of fluffy creamy white appearance in Candida endophthalmitis.

If endophthalmitis occurs, in most cases the diagnosis is based on clinical findings. Therapy is usually initiated empirically while microbiologic testing is being performed.

Early intervention is required and justified. With the introduction of intraocular sampling and intravitreal injection of antimicrobial agents, as well as the possibility for vitrectomy, management of endophthalmitis has entered a new era. The availability of such an armamentarium allows better management of endophthalmitis. However, knowledge about the likely organism that causes endophthalmitis, as well as the antimicrobial drug apt to be most effective, remains paramount.

\section{Exogenous endophthalmitis}

Historically, treatment of exogenous endophthalmitis was consisted mainly of intravenous antibiotics. ${ }^{1}$ Nevertheless, most systemically administered antibiotics do not reach sufficiently high intraocular concentrations for effective treatment of severe intraocular infections such as endophthalmitis. A more effective way to achieve a high concentration of an antimicrobial substance within the eye and the infected tissue is intravitreal drug application. Therefore, the intravitreal injection of antibiotics has become the primary method of administration in the treatment of exogenous endophthalmitis. ${ }^{1,98,99}$

Unless there is no other unequivocal result from culturing, endophthalmitis therapy should cover Gram-positive organisms, which play a predominant role in exogenous endophthalmitis. Gram-negative coverage is also important because these organisms are associated with higher virulence and poorer outcome.

Current antibiotic standard protocols for intravitreal application are empirically based and include the peptide antibiotic vancomycin $(1.0 \mathrm{mg} / 0.1 \mathrm{~mL})$ for Gram-positive coverage, ${ }^{7}$ in combination with the $\beta$-lactam antibiotic ceftazidime $(2.25 \mathrm{mg} / 0.1 \mathrm{~mL})$ for Gram-negative coverage. ${ }^{7}$ In patients sensitive to $\beta$-lactam drugs, amikacin $(400 \mu \mathrm{g} / 0.1 \mathrm{~mL})$, an aminoglycoside antibiotic, might be considered instead of ceftazidime. However, a degree of retinal toxicity of amikacin has been reported. ${ }^{100,101}$

Gram-positive organisms reportedly have a $99 \%$ susceptibility to vancomycin. ${ }^{102}$ Consequently, it has become a valuable component of endophthalmitis treatment. However, recently cases of vancomycin-resistant strains in endophthalmitis have been reported, ${ }^{103,104}$ and emerging resistance of Gram-positive pathogens to vancomycin is a concern. ${ }^{105,106}$ In addition, the EVS showed that only $89.5 \%$ of Gramnegative isolates were sensitive to amikacin or ceftazidime; ${ }^{7}$ in India, susceptibility of Gram-negative bacteria to amikacin or ceftazidime has been reported as being only $68 \%$ and $63 \%$, respectively. ${ }^{107}$

Use of fluoroquinolone antibiotics has been widely discussed as a potential alternative to current antibiotic treatment 
protocols. In particular, the recently developed third- and fourth-generation fluoroquinolones, such as levofloxacin and moxifloxacin, with their enhanced activity against Gram-positive pathogens, offer broad-spectrum activity that covers most organisms commonly encountered in bacterial endophthalmitis. ${ }^{108}$

Moxifloxacin, and fluoroquinolones in general, penetrate well into the eye. After topical administration at two-hourly intervals, moxifloxacin reaches mean aqueous concentrations of $2.3 \mu \mathrm{g} / \mathrm{mL} .{ }^{109}$ A recent study demonstrated that anterior chamber levels achieved using moxifloxacin are higher than those obtained with any other topically administered fluoroquinolone antibiotic. ${ }^{109}$ Nevertheless, intravitreal concentrations are 10 times lower than those in the anterior chamber. These levels are too low for effective treatment of intraocular infections. ${ }^{110}$ Systemic moxifloxacin does not exceed anterior chamber concentrations. It reaches intravitreal concentrations 10 times higher than levels achieved by topical use, but to reach $S$. aureus and certain fluoroquinolone-resistant strains, higher concentrations are needed. ${ }^{111}$ Therefore, direct intraocular application of such antibiotics seems useful.

Moxifloxacin is available as an unpreserved ophthalmic solution and covers both Gram-negative and -positive pathogens, including those most often implicated in the development of exogenous endophthalmitis. ${ }^{12}$ An additional potential advantage of moxifloxacin for intraocular use might be the administration of only a single substance into the eye.

Several studies have investigated the potential use of fourth-generation fluoroquinolones, and especially moxifloxacin, as prophylaxis for and treatment of endophthalmitis. ${ }^{113-119}$ In addition, pharmacokinetic data suggest intravitreal moxifloxacin is a useful alternative to current treatment protocols. ${ }^{120}$ Its safety has been demonstrated both in vivo and in vitro. ${ }^{113-117}$ An argument against use of moxifloxacin for the treatment of endophthalmitis may be that antibiotics from this group are widely used as topical antibiotics for treating superficial ocular infections and for preoperative prophylaxis. Moreover, concern exists about the emerging resistance of $S$. aureus and other Gram-positive isolates to third- and fourth-generation fluoroquinolones because of prophylactic use before and after intraocular surgery. ${ }^{53,121-123}$

These reports must be considered seriously, but it is noteworthy that sensitivity testing was determined in vitro and minimal inhibitory concentrations were based on serum levels $(8 \mathrm{mg} / \mathrm{mL})$. Recent data from toxicologic testing on ocular tissue indicate that moxifloxacin in doses up to
$150 \mu \mathrm{g} / \mathrm{mL}$ did not result in significant toxicity on several ocular cell types. ${ }^{13,114,116,117,124}$ Therefore, in vivo resistance appears to be very unlikely.

However, until these issues are resolved and its therapeutic role in endophthalmitis treatment is further elucidated, moxifloxacin should only be used in combination with an agent that is more reliable against Gram-positive pathogens.

A potential use of moxifloxacin for intracameral endophthalmitis prophylaxis in cataract surgery seems to be more reasonable. The ESCRS demonstrated that the prophylactic use of intracameral antibiotics helps to reduce the incidence of postoperative endophthalmitis after cataract surgery by $75 \% .{ }^{55}$ Therefore, prophylactic intracameral application of the $\beta$-lactam cefuroxime, together with the peptide antibiotic vancomycin, has become a beneficial and widely accepted practice for intracameral endophthalmitis prophylaxis in cataract surgery. ${ }^{125}$

However, in addition to the potential benefits, clinicians must consider that antibiotics from both groups are the mainstay of intravitreal treatment of endophthalmitis. ${ }^{7}$ Consequently, one might argue that they should be reserved for this indication and not used for prophylaxis.

Due to its broad-spectrum properties, moxifloxacin is one of the most promising candidates in endophthalmitis prophylaxis as an intracameral adjunct during cataract surgery. Nevertheless, further investigations will have to clarify the role of moxifloxacin in this context.

Systemic fluoroquinolones and antibiotics in general have been discussed as adjunctive systemic treatments for postoperative endophthalmitis. In 1995, the EVS evaluated the role of systemic antibiotics and pars plana vitrectomy in the treatment of postoperative endophthalmitis. ${ }^{7}$ The results of this study demonstrated that intravitreal antibiotics need not be supplemented with intravenous antibiotics in either acute or subacute postoperative endophthalmitis. ${ }^{7}$

Subconjunctival antibiotics may temporarily provide therapeutic levels to the anterior segment but, in general, they do not penetrate sufficiently into the vitreous cavity. ${ }^{126}$ Further, large retrospective studies did not reveal an additional benefit compared with intravitreal antibiotic application. ${ }^{127,128}$

Corticosteroids are commonly used as adjunctive treatment in bacterial as well in fungal endophthalmitis. These agents are given to modulate the inflammatory response to infection that might help to reduce secondary damage. Topical and subconjunctival steroids are widely accepted. However, use of steroids given via the systemic and intravitreal routes in the treatment of endophthalmitis remains 
controversial. A prospective, randomized trial demonstrated significantly less inflammation in endophthalmitis cases after intervention when $400 \mu \mathrm{g}$ dexamethasone was applied intravitreally. ${ }^{129}$ In contrast, visual outcome after 12 weeks was not affected. ${ }^{129}$ A recent study found a trend toward better visual acuity with adjunctive dexamethasone in a smaller series of patients with endophthalmitis. ${ }^{130}$ Other studies did not find any significant effect on inflammation or visual acuity. ${ }^{131}$ Conversely, a retrospective, nonrandomized trial of 57 patients with postoperative endophthalmitis found a significantly worse visual outcome when intravitreal dexamethasone was added to therapy. ${ }^{132}$

Pars plana vitrectomy offers several potential benefits for endophthalmitis treatment. Results from the EVS showed that immediate vitrectomy provides a clear benefit in a welldefined subgroup; patients with light perception only at the time of presentation had a significant, threefold improved chance of obtaining a visual acuity of 20/40 after vitrectomy. For diabetic patients with hand movement or better vision, at least a trend toward better final visual acuity after vitrectomy could be documented compared with vitreous tap and biopsy. ${ }^{7}$ One reason for this may be that vitrectomy results in a reduction of pathogens, toxins, inflammatory materials, and opacities. Furthermore, vitrectomy enables samples to be obtained for culture.

A potential disadvantage of vitrectomy in endophthalmitis treatment might be that this technique is not ubiquitous and therefore effective treatment might be delayed. In addition, visualization of intraocular structures might be difficult, and vitrectomy might become desperate in highly inflamed eyes. Data from different studies are inconclusive, and the overall benefit of vitrectomy in endophthalmitis is still under discussion. ${ }^{7}, 133,134$ However, the EVS addressed the relative effectiveness of immediate pars plana vitrectomy. ${ }^{7}$

One prognostic factor for the final visual outcome seems to be the type of infecting organism isolated and, in one study, if no or equivocal growth was detected in culture, $80 \%$ of cases obtained a final visual acuity of $20 / 100$ or better. ${ }^{56}$ Infections with coagulase-negative staphylococci have also been associated with a final visual acuity of 20/100 or better in the EVS population $(84 \%) .{ }^{56}$ Due to their ability to induce significant inflammation, $S$. aureus, streptococci, and Gram-negative isolates seem to result in a worse visual outcome. Other strong predictors for poor visual outcome are initial visual acuity of light perception only, older age, corneal ring ulcers, compromised posterior capsule, abnormal intraocular pressure, afferent papillary defect, rubeosis iridis, and absence of the red fundus reflex. ${ }^{56}$

\section{Endogenous endophthalmitis}

In contrast with exogenous endophthalmitis, endogenous endophthalmitis requires systemic antimicrobial therapy. The primary source of infection in endogenous endophthalmitis is outside the eye, but within the body. Therefore, systemic cultures should be obtained.

Identification of the causative pathogen by blood, urine, or cerebrospinal fluid culture is successful in more than $75 \%$ of endogenous endophthalmitis cases. ${ }^{3,4,135}$ Positive cultures from vitreous samples can be achieved much less frequently in endogenous endophthalmitis than in exogenous endophthalmitis. ${ }^{3,4,135}$ However, especially in fungal endophthalmitis, the value of obtaining an ocular culture should not be underestimated because it may be the sole source of microbial growth. In addition to cultures, in certain cases and for fastidious organisms, fungal/bacterial DNA in intraocular fluid can be detected by polymerase chain reaction assay. ${ }^{136-138}$

The role of vitrectomy in endogenous endophthalmitis is not exactly defined. One reason for this could be that data from the EVS may not be applicable because the spectrum of causative organisms differs significantly in endogenous endophthalmitis. Although systemic and intravitreal antibiotics may be sufficient in milder forms of infection, vitrectomy seems to be helpful in severe cases of endogenous endophthalmitis because more virulent organisms, such as endotoxin-producing Streptococcus and Bacillus species, are commonly involved. ${ }^{3,4}$ In addition, material from vitrectomy may provide a better source for culturing.

Patients with endogenous endophthalmitis need to have the type and extent of their disease diagnosed, complications detected, and underlying systemic cause or risk factors defined. A major target of antimicrobial therapy in endogenous endophthalmitis treatment is the source of infection, which is often guided by culture and susceptibility of the infecting organism.

Systemic antimicrobial therapy is the mainstay of endogenous endophthalmitis treatment. In most cases, treatment is initiated empirically and the infecting organism presumed to be that causing systemic infection. For intravitreal antibiotic application in bacterial infections, as with exogenous endophthalmitis treatment, vancomycin $(1.0 \mathrm{mg} / 0.1 \mathrm{~mL})$ for Gram-positive coverage or in combination with the $\beta$-lactam antibiotic ceftazidime $(2.25 \mathrm{mg} / 0.1 \mathrm{~mL})$ or amikacin $(400 \mu \mathrm{g} / 0.1 \mathrm{~mL})$ is recommended for Gram-negative coverage. In general, systemic therapy must be continued for several weeks to ensure eradication of the infection. 


\section{Fungal endophthalmitis}

Only a small number of exogenous endophthalmitis cases are thought to be fungal. However, in some tropical countries, up to $50 \%$ of central corneal ulcers are caused by fungi, ${ }^{139-142}$ and a recent review of more than 40 cases of exogenous fungal endophthalmitis revealed that almost $50 \%$ of these cases were associated with fungal keratitis. ${ }^{99}$ (see Figure 5). Therefore, exogenous fungal infections of the eye are of increasing concern.

If exogenous fungal endophthalmitis occurs, it is mostly caused by molds (mainly Fusarium and Aspergillus species) ${ }^{99}$ Nevertheless, most cases of fungal endophthalmitis are a result of endogenous fungal spread into the eye. The most commonly reported causes of endogenous fungal endophthalmitis are Candida species ( $>50 \%$ ) followed by Aspergillus and Fusarium species. ${ }^{8,90,143-145}$

In endogenous fungal endophthalmitis, treatment should be instituted as soon as the diagnosis is made, under close supervision by the attending physician. Treatment guidelines for mild forms of fungal chorioretinitis and vitreitis suggest systemic antifungal therapy combined with serial ophthalmologic examinations. ${ }^{146,147}$ Surgical intervention combined with systemic and intraocular antifungal drug application is warranted in cases of moderate or severe vitreous involvement. ${ }^{146,147}$

Most current treatment protocols recommend amphoteri$\operatorname{cin} \mathrm{B}(5-10 \mu \mathrm{g} / 0.1 \mathrm{~mL})$ and triazoles as primary therapeutic options. Both can be given systemically and intravitreally. However, the intraocular penetration of amphotericin B after topical or systemic treatment is limited, and intraocular use is associated with retinal toxicity. ${ }^{148}$ In addition, many fungal pathogens affecting the human eye are not susceptible to these agents. ${ }^{90,143}$ Recently developed second-generation triazole derivates (eg, voriconazole) seem to be promising alternatives. Voriconazole can be given either systemically or intravitreally. It penetrates well into the ocular tissue after systemic administration. ${ }^{149}$ Severe systemic side effects seem to be less common than with amphotericin B and several in vitro studies indicate that the safety profile of voriconazole after intravitreal application may be superior to that of amphotericin B. ${ }^{150-154}$ The general in vitro susceptibility of Candida, Aspergillus, and Fusarium species to voriconazole are almost $100 \% .{ }^{90}$ Numerous case reports indicate that voriconazole treatment has been successful where amphotericin B or fluconazole has failed, even in cases of drug-resistant fungal keratitis and endophthalmitis. ${ }^{152,155-160}$

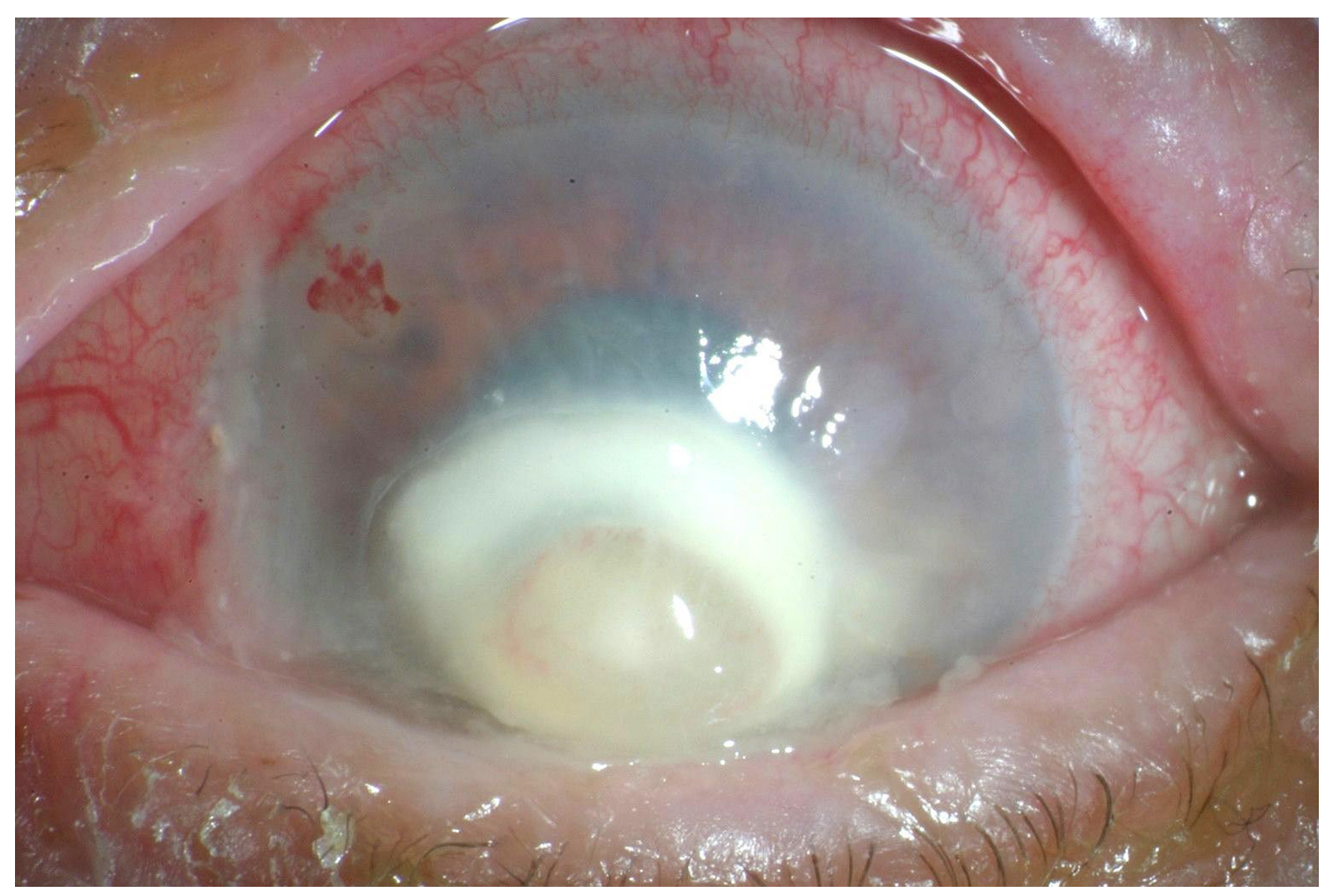

Figure 5 Exogenous fungal endophthalmitis with corneal ulcer. 
In a situation where adequate and timely treatment is essential, eyes with endogenous fungal endophthalmitis may achieve a far better final visual acuity than eyes with bacterial infections. ${ }^{6,161}$ In a larger series of endogenous fungal endophthalmitis cases, $65 \%$ of eyes achieved $20 / 400$ or better acuity. ${ }^{2}$ Nevertheless, in endogenous fungal endophthalmitis the organism isolated is critical for prognosis. Candida endophthalmitis seems to result in better outcomes than endoophthalmitis caused by Aspergillus or other fungi. ${ }^{2,5}$

Another potential treatment for endogenous fungal endophthalmitis is caspofungin, the first member of a recently introduced new class of antifungal agents known as the echinocandins. ${ }^{162,163}$ Because of their different mechanism of action, these agents are an important therapeutic alternative to currently available antifungal treatments for invasive fungal infections. Caspofungin has potent antifungal activity against Candida and Aspergillus species, which are the predominant fungal pathogens in fungal endophthalmitis. Recent reports suggest that systemic caspofungin combined with voriconazole might be an effective treatment of endophthalmitis caused by Candida, Acremonium, and Aspergillus species. ${ }^{159,164-166}$ However, the intraocular penetration properties of caspofungin after intravenous application remain unclear. ${ }^{167,168}$ One patient with advanced endogenous endophthalmitis failed to respond to caspofungin, and after nine days of a standard systemic dosage, no caspofungin could be detected intravitreally. ${ }^{167}$

Clinical experience with caspofungin in endophthalmitis treatment is limited. To date, no data are available on the potential intraocular use of caspofungin. First results from in vitro testing seem to be promising ${ }^{169}$ but need further clarification in vivo. Nevertheless, due to their unique mechanism of action and their high activity against yeasts and mold, including those commonly affecting the eye, ${ }^{170-172}$ caspofungin and other emerging drugs of this group might become more prominent in future treatment strategies for fungal endophthalmitis.

\section{Conclusion}

Endophthalmitis is one of the most devastating complications after ocular surgery or trauma and in people with systemic infection. Treatment of endophthalmitis remains challenging. Early diagnosis and treatment are essential to optimize visual outcome. Intravitreal antimicrobial drug application achieves the high intraocular substance levels needed for effective endophthalmitis treatment.

Vitrectomy seems to provide several substantial benefits in the treatment of endophthalmitis and remains accepted as a treatment option which is supplementary to intravitreal antimicrobial therapy in patients with moderate or severe disease. The EVS addressed the relative effectiveness of immediate pars plana vitrectomy after postoperative endophthalmitis. ${ }^{7}$ However, a general advantage of vitrectomy in endophthalmitis is still under discussion.

In general, for exogenous endophthalmitis treatment, intravitreal antibiotics need not be supplemented with intravenous antibiotics. In contrast, most cases of endogenous endophthalmitis, where the primary focus of infection is outside the eye, require systemic antimicrobial therapy. Supplementary intravitreal drug application and vitrectomy may be supportive.

In fungal endophthalmitis, vitrectomy and intravitreal amphotericin B are indicated in case of severe vitreous involvement. Recent advances in therapy using antimycotic drugs, including the second-generation triazole agent voriconazole and the echinocandin caspofungin, may offer new treatment options to manage fungal endophthalmitis, but these drugs need further evaluation.

\section{Disclosures}

The authors do not have any commercial or financial interest in any of the materials or methods used in this study.

\section{References}

1. Mamalis N. Endophthalmitis. J Cataract Refract Surg. 2002;28(5): 729-730.

2. Essman TF, Flynn HW Jr, Smiddy WE, et al. Treatment outcomes in a 10-year study of endogenous fungal endophthalmitis. Ophthalmic Surg Lasers. 1997;28(3):185-194.

3. Jackson TL, Eykyn SJ, Graham EM, Stanford MR. Endogenous bacterial endophthalmitis: 17-year prospective series and review of 267 reported cases. Surg Ophthalmol. 2003;48(4):403-423.

4. Okada AA, Johnson RP, Liles WC, D'Amico DJ, Baker AS. Endogenous bacterial endophthalmitis. Report of a ten-year retrospective study. Ophthalmology. 1994;101(5):832-838.

5. Rao NA, Hidayat AA. Endogenous mycotic endophthalmitis: Variations in clinical and histopathologic changes in candidiasis compared with aspergillosis. Am J Ophthalmol. 2001;132(2):244-251.

6. Tanaka M, Kobayashi Y, Takebayashi H, Kiyokawa M, Qiu H. Analysis of predisposing clinical and laboratory findings for the development of endogenous fungal endophthalmitis. A retrospective 12-year study of 79 eyes of 46 patients. Retina. 2001;21(3):203-209.

7. Results of the Endophthalmitis Vitrectomy Study. A randomized trial of immediate vitrectomy and of intravenous antibiotics for the treatment of postoperative bacterial endophthalmitis. Endophthalmitis Vitrectomy Study Group. Arch Ophthalmol. 1995;113(12):1479-1496.

8. Essex RW, Yi Q, Charles PG, Allen PJ. Post-traumatic endophthalmitis. Ophthalmology. 2004;111(11):2015-2022.

9. Kattan HM, Flynn HW Jr, Pflugfelder SC, Robertson C, Forster RK. Nosocomial endophthalmitis survey. Current incidence of infection after intraocular surgery. Ophthalmology. 1991;98(2):227-238.

10. Aaberg TM Jr, Flynn HW Jr, Schiffman J, Newton J. Nosocomial acute-onset postoperative endophthalmitis survey. A 10-year review of incidence and outcomes. Ophthalmology. 1998;105(6):1004-1010. 
11. Bainbridge JW, Teimory $\mathrm{M}$, Tabandeh $\mathrm{H}$, et al. Intraocular lens implants and risk of endophthalmitis. Br J Ophthalmol. 1998;82(11): $1312-1315$.

12. Javitt JC, Street DA, Tielsch JM, et al. National outcomes of cataract extraction. Retinal detachment and endophthalmitis after outpatient cataract surgery. Cataract Patient Outcomes Research Team. Ophthalmology. 1994;101(1):100-105; discussion 106.

13. Mamalis N, Nagpal M, Nagpal K, Nagpal PN. Endophthalmitis following cataract surgery. Ophthalmol Clin North Am. 2001;14(4): $661-674$, ix.

14. Morlet N, Gatus B, Coroneo M. Patterns of peri-operative prophylaxis for cataract surgery: A survey of Australian ophthalmologists. Aust $N$ Z J Ophthalmol. 1998;26(1):5-12.

15. Morlet N, Li J, Semmens J, Ng J. The Endophthalmitis Population Study of Western Australia (EPSWA): First report. Br J Ophthalmol. 2003;87(5):574-576.

16. Taban M, Behrens A, Newcomb RL, et al. Acute endophthalmitis following cataract surgery: A systematic review of the literature. Arch Ophthalmol. 2005;123(5):613-620.

17. Cooper BA, Holekamp NM, Bohigian G, Thompson PA. Case-control study of endophthalmitis after cataract surgery comparing scleral tunnel and clear corneal wounds. Am J Ophthalmol. 2003;136(2): 300-305.

18. Nagaki Y, Hayasaka S, Kadoi C, et al. Bacterial endophthalmitis after small-incision cataract surgery. Effect of incision placement and intraocular lens type. J Cataract Refract Surg. 2003;29(1):20-26.

19. Lalwani GA, Flynn HW Jr, et al. Acute-onset endophthalmitis after clear corneal cataract surgery (1996-2005). Clinical features, causative organisms, and visual acuity outcomes. Ophthalmology. 2008;115(3):473-476.

20. Eifrig CW, Flynn HW Jr, Scott IU, Newton J. Acute-onset postoperative endophthalmitis: Review of incidence and visual outcomes (19952001). Ophthalmic Surg Lasers. 2002;33(5):373-378.

21. Scott IU, Flynn HW Jr, Dev S, Shaikh S, Mittra RA, Arevalo JF, et al. Endophthalmitis after 25-gauge and 20-gauge pars plana vitrectomy: Incidence and outcomes. Retina. 2008;28(1):138-142.

22. Cantrill HL, Henry K, Melroe NH, Knobloch WH, Ramsay RC, Balfour HH Jr. Treatment of cytomegalovirus retinitis with intravitreal ganciclovir. Long-term results. Ophthalmology. 1989;96(3): 367-374.

23. Jager RD, Aiello LP, Patel SC, Cunningham ET Jr. Risks of intravitreous injection: A comprehensive review. Retina. 2004;24(5):676-698.

24. Ciulla TA, Baker AS. Endophthalmitis following glaucoma filtering surgery. Int Ophthalmol Clin. 1996;36(3):87-96.

25. Al-Torbak AA, Al-Shahwan S, Al-Jadaan I, Al-Hommadi A, Edward DP. Endophthalmitis associated with the Ahmed glaucoma valve implant. Br J Ophthalmol. 2005;89(4):454-458.

26. Hassan SS, Wilhelmus KR, Dahl P, Davis GC, Roberts RT, Ross KW, et al. Infectious disease risk factors of corneal graft donors. Arch Ophthalmol. 2008;126(2):235-239.

27. Muckley ED, Lehrer RA. Late-onset blebitis/endophthalmitis: Incidence and outcomes with mitomycin C. Optom Vis Sci. 2004;81(7): 499-504.

28. Sharan S, Trope GE, Chipman M, Buys YM. Late-onset bleb infections: Prevalence and risk factors. Can J Ophthalmol. 2009;44(3):279-283.

29. Greenfield DS, Suner IJ, Miller MP, Kangas TA, Palmberg PF, Flynn HW Jr. Endophthalmitis after filtering surgery with mitomycin. Arch Ophthalmol. 1996;114(8):943-949.

30. Kangas TA, Greenfield DS, Flynn HW Jr, Parrish RK 2nd, Palmberg P. Delayed-onset endophthalmitis associated with conjunctival filtering blebs. Ophthalmology. 1997;104(5):746-752.

31. Song A, Scott IU, Flynn HW Jr, Budenz DL. Delayed-onset blebassociated endophthalmitis: Clinical features and visual acuity outcomes. Ophthalmology. 2002;109(5):985-991.

32. Wolner B, Liebmann JM, Sassani JW, Ritch R, Speaker M, Marmor M. Late bleb-related endophthalmitis after trabeculectomy with adjunctive 5-fluorouracil. Ophthalmology. 1991;98(7):1053-1060.
33. Higginbotham EJ, Stevens RK, Musch DC, Karp KO, Lichter PR, Bergstrom TJ, et al. Bleb-related endophthalmitis after trabeculectomy with mitomycin C. Ophthalmology. 1996;103(4):650-656.

34. Peponis V, Rosenberg P, Chalkiadakis SE, Insler M, Amariotakis A. Fungal scleral keratitis and endophthalmitis following pterygium excision. Eur J Ophthalmol. 2009;19(3):478-480.

35. Khurshid GS, Fahy GT. Endophthalmitis secondary to corneal sutures: Series of delayed-onset keratitis requiring intravitreal antibiotics. J Cataract Refract Surg. 2003;29(7):1370-1372.

36. Duker JS, Belmont JB. Late bacterial endophthalmitis following retinal detachment surgery. Retina. 1989;9(4):263-266.

37. Pathengay A, Karosekar S, Raju B, Sharma S, Das T. Microbiologic spectrum and susceptibility of isolates in scleral buckle infection in India. Am J Ophthalmol. 2004;138(4):663-664.

38. Recchia FM, Baumal CR, Sivalingam A, Kleiner R, Duker JS, Vrabec TR. Endophthalmitis after pediatric strabismus surgery. Arch Ophthalmol. 2000;118(7):939-944.

39. Proenca-Pina J, Ssi Yan Kai I, Bourcier T, Fabre M, Offret H, Labetoulle M. Fusarium keratitis and endophthalmitis associated with lens contact wear. Int Ophthalmol. 2010;30(1):103-107.

40. Lopez PF, Beldavs RA, al-Ghamdi S, Wilson LA, Wojno TH, Sternberg $\mathrm{P} J \mathrm{r}$, et al. Pneumococcal endophthalmitis associated with nasolacrimal obstruction. Am J Ophthalmol. 1993;116(1):56-62.

41. Mino de Kaspar H, Shriver EM, Nguyen EV, et al. Risk factors for antibiotic-resistant conjunctival bacterial flora in patients undergoing intraocular surgery. Graefes Arch Clin Exp Ophthalmol. 2003;241(9):730-733.

42. Dortzbach RK, Woog JJ. Choice of procedure. Enucleation, evisceration, or prosthetic fitting over globes. Ophthalmology. 1985;92(9): 1249-1255.

43. Mino de Kaspar H, Grasbon T, Kampik A. Automated surgical equipment requires routine disinfection of vacuum control manifold to prevent postoperative endophthalmitis. Ophthalmology. 2000;107(4):685-690.

44. Roy M, Chen JC, Miller M, Boyaner D, Kasner O, Edelstein E. Epidemic Bacillus endophthalmitis after cataract surgery I: Acute presentation and outcome. Ophthalmology. 1997;104(11):1768-1772.

45. Zaluski S, Clayman HM, Karsenti G, et al. Pseudomonas aeruginosa endophthalmitis caused by contamination of the internal fluid pathways of a phacoemulsifier. J Cataract Refract Surg. 1999;25(4):540-545.

46. Montan PG, Koranyi G, Setterquist HE, Stridh A, Philipson BT, Wiklund K. Endophthalmitis after cataract surgery: Risk factors relating to technique and events of the operation and patient history. A retrospective case-control study. Ophthalmology. 1998;105(12):2171-2177.

47. Schmitz S, Dick HB, Krummenauer F, Pfeiffer N. Endophthalmitis in cataract surgery: Results of a German survey. Ophthalmology. 1999;106(10):1869-1877.

48. Gallenga PE, Mastropasqua L, Carpineto P, et al. In vitro Staphylococcus epidermidis growth in some viscoelastic substances containing sodium hyaluronate. Ophthalmologica. 1998;212(3):184-187.

49. Mastropasqua L, Piccolomini R, Carpineto P, et al. In vitro viability of external eye microbial flora in hydroxy-propyl-methylcellulose. Ophthalmologica. 1999;213(4):265-268.

50. Mamalis N, Kearsley L, Brinton E. Postoperative endophthalmitis. Curr Opin Ophthalmol. 2002;13(1):14-18.

51. Breitbach R, Spitznas M. Perioperative risk of infection in cataract surgery. Klin Monatsbl Augenheilkd. 1991;198(2):94-98.

52. Meredith TA, Trabelsi A, Miller MJ, Aguilar E, Wilson LA. Spontaneous sterilization in experimental Staphylococcus epidermidis endophthalmitis. Invest Ophthalmol Vis Sci. 1990;31(1):181-186.

53. Kunimoto DY, Das T, Sharma S, et al. Microbiologic spectrum and susceptibility of isolates: Part I. Postoperative endophthalmitis. Endophthalmitis Research Group. Am J Ophthalmol. 1999;128(2): 240-242.

54. Moshfeghi DM, Kaiser PK, Scott IU, et al. Acute endophthalmitis following intravitreal triamcinolone acetonide injection. $\mathrm{Am} \mathrm{J}$ Ophthalmol. 2003;136(5):791-796. 
55. Prophylaxis of postoperative endophthalmitis following cataract surgery: Results of the ESCRS multicenter study and identification of risk factors. J Cataract Refract Surg. 2007;33(6):978-988.

56. No authors listed. Microbiologic factors and visual outcome in the endophthalmitis vitrectomy study. Am J Ophthalmol. 1996;122(6): 830-846.

57. Mao LK, Flynn HW Jr, Miller D, Pflugfelder SC. Endophthalmitis caused by streptococcal species. Arch Ophthalmol. 1992;110(6): 798-801.

58. Miller JJ, Scott IU, Flynn HW Jr, Smiddy WE, Corey RP, Miller D. Endophthalmitis caused by Streptococcus pneumoniae. Am JOphthalmol. 2004;138(2):231-236.

59. Soriano F, Perez-Trallero E, Pallares R, et al. Streptococcus pneumoniae endophthalmitis: A study of 36 cases with special reference to antibiotic resistance and treatment options. Clin Microbiol Infect 2006;12(6):519-526.

60. Pinna A, Sechi LA, Zanetti S, Delogu D, Carta F. Adherence of ocular isolates of staphylococcus epidermidis to ACRYSOF intraocular lenses. A scanning electron microscopy and molecular biology study. Ophthalmology. 2000;107(12):2162-2166.

61. Pinna A, Zanetti S, Sechi LA, Usai D, Falchi MP, Carta F. In vitro adherence of Staphylococcus epidermidis to polymethyl methacrylate and ACRYSOF intraocular lenses. Ophthalmology. 2000;107(6) 1042-1046.

62. Affeldt JC, Flynn HW Jr, Forster RK, Mandelbaum S, Clarkson JG, Jarus GD. Microbial endophthalmitis resulting from ocular trauma. Ophthalmology. 1987;94(4):407-413.

63. Brinton GS, Topping TM, Hyndiuk RA, Aaberg TM, Reeser FH, Abrams GW. Posttraumatic endophthalmitis. Arch Ophthalmol. 1984;102(4):547-550.

64. Kresloff MS, Castellarin AA, Zarbin MA. Endophthalmitis. Surv Ophthalmol. 1998;43(3):193-224.

65. Chaudhry IA, Shamsi FA, A1-Harthi E, Al-Theeb A, Elzaridi E, Riley FC. Incidence and visual outcome of endophthalmitis associated with intraocular foreign bodies. Graefes Arch Clin Exp Ophthalmol. 2008;246(2):181-186.

66. Ariyasu RG, Kumar S, LaBree LD, Wagner DG, Smith RE. Microorganisms cultured from the anterior chamber of ruptured globes at the time of repair. Am J Ophthalmol. 1995;119(2):181-188.

67. Rubsamen PE, Cousins SW, Martinez JA. Impact of cultures on management decisions following surgical repair of penetrating ocular trauma. Ophthalmic Surg Lasers. 1997;28(1):43-49.

68. Thompson JT, Parver LM, Enger CL, Mieler WF, Liggett PE. Infectious endophthalmitis after penetrating injuries with retained intraocular foreign bodies. National Eye Trauma System. Ophthalmology. 1993;100(10):1468-1474.

69. Thompson WS, Rubsamen PE, Flynn HW Jr, Schiffman J, Cousins SW. Endophthalmitis after penetrating trauma. Risk factors and visual acuity outcomes. Ophthalmology. 1995;102(11):1696-1701.

70. Zhang Y, Zhang M, Jiang C, Yao Y, Zhang K. Endophthalmitis following open globe Injury. Br J Ophthalmol. Epub ahead of print. 2009 Aug 18.

71. Hooi SH, Hooi ST. Open-globe injuries: The experience at Hospital Sultanah Aminah, Johor Bahru. Med J Malaysia. 2003;58(3): 405-412.

72. Sabaci G, Bayer A, Mutlu FM, Karagul S, Yildirim E. Endophthalmitis after deadly-weapon-related open-globe injuries: Risk factors, value of prophylactic antibiotics, and visual outcomes. Am J Ophthalmol. 2002;133(1):62-69.

73. Schrader WF. Epidemiology of open globe eye injuries: Analysis of 1026 cases in 18 years. Klin Monbl Augenheilkd. 2004;221(8): 629-635.

74. Alfaro DV, Roth DB, Laughlin RM, Goyal M, Liggett PE. Paediatric post-traumatic endophthalmitis. Br J Ophthalmol. 1995;79(10) 888-891.

75. Verbraeken H, Rysselaere M. Post-traumatic endophthalmitis. Eur J Ophthalmol. 1994;4(1):1-5.
76. Williams DF, Mieler WF, Abrams GW, Lewis H. Results and prognostic factors in penetrating ocular injuries with retained intraocular foreign bodies. Ophthalmology. 1988;95(7):911-916.

77. Bohigian GM, Olk RJ. Factors associated with a poor visual result in endophthalmitis. Am J Ophthalmol. 1986;101(3):332-341.

78. Ness T, Pelz K. Endophthalmitis: Improvement of culture results. Ophthalmologe. 2000;97(1):33-37.

79. Chee SP, Jap A. Endogenous endophthalmitis. Curr Opin Ophthalmol. 2001;12(6):464-470.

80. Shrader SK, Band JD, Lauter CB, Murphy P. The clinical spectrum of endophthalmitis: Incidence, predisposing factors, and features influencing outcome. J Infect Dis. 1990;162(1):115-120.

81. Brod RD, Flynn HW Jr, Clarkson JG, Pflugfelder SC, Culbertson WW, Miller D. Endogenous Candida endophthalmitis. Management without intravenous amphotericin B. Ophthalmology. 1990;97(5):666-672; discussion 672-674

82. Nakayama F, Soloway RD, Nakama T, et al. Hepatolithiasis in East Asia. Retrospective study. Dig Dis Sci. 1986;31(1):21-26.

83. Wong JS, Chan TK, Lee HM, Chee SP. Endogenous bacterial endophthalmitis: An east Asian experience and a reappraisal of a severe ocular affliction. Ophthalmology. 2000;107(8):1483-1491.

84. Chen YJ, Kuo HK, Wu PC, et al. A 10-year comparison of endogenous endophthalmitis outcomes: An east Asian experience with Klebsiella pneumoniae infection. Retina. 2004;24(3):383-390.

85. Ness T, Pelz K, Hansen LL. Endogenous endophthalmitis: Microorganisms, disposition and prognosis. Acta Ophthalmol Scand. 2007;85(8):852-856.

86. Sallam A, Lynn W, McCluskey P, Lightman S. Endogenous Candida endophthalmitis. Expert Rev Anti Infect Ther. 2006;4(4):675-685.

87. Chen YC, Chang SC, Luh KT, Hsieh WC. Stable susceptibility of Candida blood isolates to fluconazole despite increasing use during the past 10 years. J Antimicrob Chemother. 2003;52(1):71-77.

88. Kibbler CC, Seaton S, Barnes RA, et al. Management and outcome of bloodstream infections due to Candida species in England and Wales. $J$ Hosp Infect. 2003;54(1):18-24.

89. Pfaller MA, Diekema DJ, Messer SA, Boyken L, Hollis RJ. Activities of fluconazole and voriconazole against 1,586 recent clinical isolates of Candida species determined by Broth microdilution, disk diffusion, and Etest methods: Report from the ARTEMIS Global Antifungal Susceptibility Program, 2001. J Clin Microbiol. 2003;41(4):1440-1446.

90. Marangon FB, Miller D, Giaconi JA, Alfonso EC. In vitro investigation of voriconazole susceptibility for keratitis and endophthalmitis fungal pathogens. Am J Ophthalmol. 2004;137(5):820-825.

91. Kostick DA, Foster RE, Lowder CY, Meyers SM, McHenry MC. Endogenous endophthalmitis caused by Candida albicans in a healthy woman. Am J Ophthalmol. 1992;113(5):593-595.

92. Brooks RG. Prospective study of Candida endophthalmitis in hospitalized patients with candidemia. Arch Intern Med. 1989;149(10): 2226-2228.

93. Krishna R, Amuh D, Lowder CY, Gordon SM, Adal KA, Hall G. Should all patients with candidaemia have an ophthalmic examination to rule out ocular candidiasis? Eye. 2000;14(Pt 1):30-34.

94. Feman SS, Nichols JC, Chung SM, Theobald TA. Endophthalmitis in patients with disseminated fungal disease. Trans Am Ophthalmol Soc. 2002;100:67-70; discussion 70-71.

95. Pappas PG, Rex JH, Lee J, et al. A prospective observational study of candidemia: Epidemiology, therapy, and influences on mortality in hospitalized adult and pediatric patients. Clin Infect Dis. 2003;37(5): 634-643.

96. Donahue SP, Greven CM, Zuravleff JJ, et al. Intraocular candidiasis in patients with candidemia. Clinical implications derived from a prospective multicenter study. Ophthalmology. 1994;101(7): 1302-1309.

97. Rodriguez-Adrian LJ, King RT, Tamayo-Derat LG, Miller JW, Garcia CA, Rex JH. Retinal lesions as clues to disseminated bacterial and candidal infections: Frequency, natural history, and etiology. Medicine (Baltimore). 2003;82(3):187-202. 
98. Maguire JI. Postoperative endophthalmitis: Optimal management and the role and timing of vitrectomy surgery. Eye (Lond). 2008;22(10):1290-1300.

99. Wykoff CC, Flynn HW Jr, Miller D, Scott IU, Alfonso EC. Exogenous fungal endophthalmitis: Microbiology and clinical outcomes. Ophthalmology. 2008;115(9):1501-1507.

100. Jackson TL, Williamson TH. Amikacin retinal toxicity. $\mathrm{Br} J$ Ophthalmol. 1999;83(10):1199-1200.

101. Seawright AA, Bourke RD, Cooling RJ. Macula toxicity after intravitreal amikacin. Aust N Z J Ophthalmol. 1996;24(2):143-146.

102. Recchia FM, Busbee BG, Pearlman RB, Carvalho-Recchia CA, Ho AC. Changing trends in the microbiologic aspects of postcataract endophthalmitis. Arch Ophthalmol. 2005;123(3):341-346.

103. Bains HS, Weinberg DV, Feder RS, Noskin GA. Postoperative vancomycin-resistant Enterococcus faecium endophthalmitis. Arch Ophthalmol. 2007;125(9):1292-1293.

104. Esmaeli B, Holz ER, Ahmadi MA, Krathen RA, Raad II. Endogenous endophthalmitis secondary to vancomycin-resistant enterococciinfection. Retina. 2003;23(1):118-119.

105. Nucci C, Artini M, Pasmore M, Missiroli F, Costerton JW, Selan L. A microbiological and confocal microscopy study documenting a slime-producing Staphylococcus epidermidis isolated from a nylon corneal suture of a patient with antibiotic-resistant endophthalmitis. Graefes Arch Clin Exp Ophthalmol. 2005;243(9):951-954.

106. Smith TL, Pearson ML, Wilcox KR, et al. Emergence of vancomycin resistance in Staphylococcus aureus. Glycopeptide-Intermediate Staphylococcus aureus Working Group. N Engl J Med. 1999;340(7): 493-501.

107. Anand AR, Therese KL, Madhavan HN. Spectrum of aetiological agents of postoperative endophthalmitis and antibiotic susceptibility of bacterial isolates. Indian J Ophthalmol. 2000;48(2):123-128.

108. Callegan MC, Ramirez R, Kane ST, Cochran DC, Jensen H. Antibacterial activity of the fourth-generation fluoroquinolones gatifloxacin and moxifloxacin against ocular pathogens. Adv Ther. 2003;20(5): 246-252.

109. McCulley JP, Caudle D, Aronowicz JD, Shine WE. Fourth-generation fluoroquinolone penetration into the aqueous humor in humans. Ophthalmology. 2006;113(6):955-959.

110. Hariprasad SM, Blinder KJ, Shah GK, et al. Penetration pharmacokinetics of topically administered $0.5 \%$ moxifloxacin ophthalmic solution in human aqueous and vitreous. Arch Ophthalmol. 2005;123(1):39-44.

111. Gao H, Pennesi ME, Qiao X, et al. Intravitreal moxifloxacin: Retinal safety study with electroretinography and histopathology in animal models. Invest Ophthalmol Vis Sci. 2006;47(4):1606-1611.

112. Kernt M, Hirneiss C, Neubauer AS, Liegl RG, Eibl KH, Wolf A, et al. Intracameral moxifloxacin: A safe option for endophthalmitis prophylaxis? : In vitro safety profile for intraocular application. Ophthalmologe. Epub ahead of print 2009 Sep 17.

113. Ermis SS, Cetinkaya Z, Kiyici H, Inan UU, Ozturk F. Effects of intravitreal moxifloxacin and dexamethasone in experimental Staphylococcus aureus endophthalmitis. Curr Eye Res. 2007;32(4):337-344.

114. Ermis SS, Cetinkaya Z, Kiyici H, Ozturk F. Treatment of Staphylococcus epidermidis endophthalmitis with intravitreal moxifloxacin in a rabbit model. Tohoku J Exp Med. 2005;205(3):223-229.

115. Kowalski RP, Dhaliwal DK, Karenchak LM, et al. Gatifloxacin and moxifloxacin: An in vitro susceptibility comparison to levofloxacin, ciprofloxacin, and ofloxacin using bacterial keratitis isolates. $\mathrm{Am} J$ Ophthalmol. 2003;136(3):500-505.

116. Kernt M, Neubauer AS, Liegl RG, et al. Intracameral moxifloxacin: In vitro safety on human ocular cells. Cornea. 2009;28(5):553-561.

117. Kernt M, Neubauer AS, Ulbig MW, Kampik A, Welge-Lussen U. In vitro safety of intravitreal moxifloxacin for endophthalmitis treatment. J Cataract Refract Surg. 2008;34(3):480-488.

118. Lott MN, Fuller JJ, Hancock HA, et al. Vitreal penetration of oral moxifloxacin in humans. Retina. 2008;28(3):473-476.
119. Yagci R, Oflu Y, Dincel A, et al. Penetration of second-, third-, and fourth-generation topical fluoroquinolone into aqueous and vitreous humour in a rabbit endophthalmitis model. Eye (Lond). 2007;21(7):990-994.

120. Iyer MN, He F, Wensel TG, Mieler WF, Benz MS, Holz ER. Intravitreal clearance of moxifloxacin. Trans Am Ophthalmol Soc. 2005;103:76-81; discussion 81-83.

121. Deramo VA, Lai JC, Fastenberg DM, Udell IJ. Acute endophthalmitis in eyes treated prophylactically with gatifloxacin and moxifloxacin. Am J Ophthalmol. 2006;142(5):721-725.

122. Goldstein MH, Kowalski RP, Gordon YJ. Emerging fluoroquinolone resistance in bacterial keratitis: A 5-year review. Ophthalmology. 1999;106(7):1313-1318.

123. Kunimoto DY, Sharma S, Garg P, Rao GN. In vitro susceptibility of bacterial keratitis pathogens to ciprofloxacin. Emerging resistance. Ophthalmology. 1999;106(1):80-805.

124. Kowalski RP, Romanowski EG, Mah FS, Yates KA, Gordon YJ. Intracameral Vigamox (moxifloxacin $0.5 \%$ ) is non-toxic and effective in preventing endophthalmitis in a rabbit model. Am J Ophthalmol. 2005;140(3):497-504.

125. Masket S. Preventing, diagnosing, and treating endophthalmitis. $J$ Cataract Refract Surg. 1998;24(6):725-726.

126. Barza M, Doft B, Lynch E. Ocular penetration of ceftriaxone, ceftazidime, and vancomycin after subconjunctival injection in humans. Arch Ophthalmol. 1993;111(4):492-494.

127. Iyer MN, Han DP, Yun HJ, et al. Subconjunctival antibiotics for acute postcataract extraction endophthalmitis - is it necessary? Am J Ophthalmol. 2004;137(6):1120-1121.

128. Smiddy WE, Smiddy RJ, Ba'Arath B, et al. Subconjunctival antibiotics in the treatment of endophthalmitis managed without vitrectomy. Retina. 2005;25(6):751-758.

129. Das T, Jalali S, Gothwal VK, Sharma S, Naduvilath TJ. Intravitreal dexamethasone in exogenous bacterial endophthalmitis: Results of a prospective randomised study. Br J Ophthalmol. 1999;83(9): 1050-1055.

130. Gan IM, Ugahary LC, van Dissel JT, et al. Intravitreal dexamethasone as adjuvant in the treatment of postoperative endophthalmitis: A prospective randomized trial. Graefes Arch Clin Exp Ophthalmol. 2005;243(12):1200-1205.

131. Hall EF, Scott GR, Musch DC, Zacks DN. Adjunctive intravitreal dexamethasone in the treatment of acute endophthalmitis following cataract surgery. Clin Ophthalmol. 2008;2(1):139-145.

132. Shah GK, Stein JD, Sharma S, Sivalingam A, et al. Visual outcomes following the use of intravitreal steroids in the treatment of postoperative endophthalmitis. Ophthalmology. 2000;107(3): 486-489.

133. Doft BH, Kelsey SF, Wisniewski SR. Additional procedures after the initial vitrectomy or tap-biopsy in the Endophthalmitis Vitrectomy Study. Ophthalmology. 1998;105(4):707-716.

134. Kuhn F, Gini G. Ten years after ... are findings of the Endophthalmitis Vitrectomy Study still relevant today? Graefes Arch Clin Exp Ophthalmol. 2005;243(12):1197-1199.

135. Greenwald MJ, Wohl LG, Sell CH. Metastatic bacterial endophthalmitis: A contemporary reappraisal. Surv Ophthalmol. 1986;31(2): 81-101.

136. Jaeger EE, Carroll NM, Choudhury S, et al. Rapid detection and identification of Candida, Aspergillus, and Fusarium species in ocular samples using nested PCR. J Clin Microbiol. 2000;38(8): 2902-2908.

137. Lohmann CP, Linde HJ, Reischl U. Improved detection of microorganisms by polymerase chain reaction in delayed endophthalmitis after cataract surgery. Ophthalmology. 2000;107(6):1047-1051; discussion 1051-1052.

138. Okhravi N, Adamson P, Carroll N, et al. PCR-based evidence of bacterial involvement in eyes with suspected intraocular infection. Invest Ophthalmol Vis Sci. 2000;41(11):3474-3479. 
139. Dunlop AA, Wright ED, Howlader SA, et al. Suppurative corneal ulceration in Bangladesh. A study of 142 cases examining the microbiological diagnosis, clinical and epidemiological features of bacterial and fungal keratitis. Aust NZ J Ophthalmol. 1994;22(2):105-110.

140. Polack FM, Kaufman HE, Newmark E. Keratomycosis. Medical and surgical treatment. Arch Ophthalmol. 1971;85(4):410-416.

141. Srinivasan M, Gonzales CA, George C, et al. Epidemiology and aetiological diagnosis of corneal ulceration in Madurai, south India. Br J Ophthalmol. 1997;81(11):965-971.

142. Thomas PA. Mycotic keratitis - an underestimated mycosis. J Med Vet Mycol. 1994;32(4):235-256.

143. Benz MS, Scott IU, Flynn HW Jr, Unonius N, Miller D. Endophthalmitis isolates and antibiotic sensitivities: A 6-year review of cultureproven cases. Am J Ophthalmol. 2004;137(1):38-42.

144. Keswani T, Ahuja V, Changulani M. Evaluation of outcome of various treatment methods for endogenous endophthalmitis. Indian J Med Sci. 2006;60(11):454-460.

145. Narang S, Gupta A, Gupta V, et al. Fungal endophthalmitis following cataract surgery: Clinical presentation, microbiological spectrum, and outcome. Am J Ophthalmol. 2001;132(5):609-617.

146. Pappas PG, Rex JH, Sobel JD, et al. Guidelines for treatment of candidiasis. Clin Infect Dis. 2004;38(2):161-189.

147. Pappas PG, Kauffman CA, Andes D, et al. Clinical practice guidelines for the management of candidiasis: 2009 update by the Infectious Diseases Society of America. Clin Infect Dis. 2009;48(5):503-535.

148. Axelrod AJ, Peyman GA, Apple DJ. Toxicity of intravitreal injection of amphotericin B. Am J Ophthalmol. 1973;76(4):578-583.

149. Hariprasad SM, Mieler WF, Holz ER, et al. Determination of vitreous, aqueous, and plasma concentration of orally administered voriconazole in humans. Arch Ophthalmol. 2004;122(1):42-47.

150. Herbrecht R. Voriconazole: Therapeutic review of a new azole antifungal. Expert Rev Anti Infect Ther. 2004;2(4):485-497.

151. Gao H, Pennesi ME, Shah K, et al. Intravitreal voriconazole: An electroretinographic and histopathologic study. Arch Ophthalmol. 2004;122(11):1687-1692.

152. Kramer M, Kramer MR, Blau H, Bishara J, Axer-Siegel R, Weinberger D. Intravitreal voriconazole for the treatment of endogenous Aspergillus endophthalmitis. Ophthalmology. 2006;113(7):1184-1186.

153. Kernt M, Kampik A. Intracameral voriconazole: In vitro safety for human ocular cells. Toxicology. 2009;258(2-3):84-93.

154. Kernt M, Neubauer AS, De Kaspar HM, Kampik A. Intravitreal voriconazole: In vitro safety-profile for fungal endophthalmitis. Retina. 2009;29(3):362-370.

155. Bunya VY, Hammersmith KM, Rapuano CJ, Ayres BD, Cohen EJ. Topical and oral voriconazole in the treatment of fungal keratitis. Am J Ophthalmol. 2007;143(1):151-153.

156. Creti A, Esposito V, Bocchetti M, et al. Voriconazole curative treatment for Acremonium species keratitis developed in a patient with concomitant Staphylococcus aureus corneal infection: A case report In Vivo. 2006;20(1):169-171.

157. Freda R. Use of oral voriconazole as adjunctive treatment of severe cornea fungal infection: Case report. Arq Bras Oftalmol. 2006;69(3):431-434.

Clinical Ophthalmology

\section{Publish your work in this journal}

Clinical Ophthalmology is an international, peer-reviewed journal covering all subspecialties within ophthalmology. Key topics include: Optometry; Visual science; Pharmacology and drug therapy in eye diseases; Basic Sciences; Primary and Secondary eye care; Patient Safety and Quality of Care Improvements. This journal is indexed on
158. OzbekZ, Kang S, Sivalingam J, Rapuano CJ, Cohen EJ, Hammersmith KM. Voriconazole in the management of Alternaria keratitis. Cornea. 2006;25(2):242-244.

159. Durand ML, Kim IK, D'Amico DJ, et al. Successful treatment of Fusarium endophthalmitis with voriconazole and Aspergillus endophthalmitis with voriconazole plus caspofungin. Am JOphthalmol. 2005;140(3):552-554.

160. Nehemy MB, Vasconcelos-Santos DV, Torqueti-Costa L, Magalhaes EP. Chronic endophthalmitis due to verticillium species after cataract surgery treated (or managed) with pars plana vitrectomy and oral and intravitreal voriconazole. Retina. 2006;26(2):225-227.

161. Binder MI, Chua J, Kaiser PK, Procop GW, Isada CM. Endogenous endophthalmitis: An 18-year review of culture-positive cases at a tertiary care center. Medicine (Baltimore). 2003;82(2):97-105.

162. Agarwal MB, Rathi SA, Ratho N, Subramanian R. Caspofungin: Major breakthrough in treatment of systemic fungal infections. J Assoc Physicians India. 2006;54:943-948.

163. Theuretzbacher U. Pharmacokinetics/pharmacodynamics of echinocandins. Eur J Clin Microbiol Infect Dis. 2004;23(11): 805-812.

164. Breit SM, Hariprasad SM, Mieler WF, Shah GK, Mills MD, Grand MG. Management of endogenous fungal endophthalmitis with voriconazole and caspofungin. Am J Ophthalmol. 2005;139(1):135-140.

165. Cornely OA, Schmitz K, Aisenbrey S. The first echinocandin: Caspofungin. Mycoses. 2002;45 Suppl 3:56-60.

166. Sarria JC, Bradley JC, Habash R, Mitchell KT, Kimbrough RC, Vidal AM. Candida glabrata endophthalmitis treated successfully with caspofungin. Clin Infect Dis. 2005;40(5):e46-e48.

167. Gauthier GM, Nork TM, Prince R, Andes D. Subtherapeutic ocular penetration of caspofungin and associated treatment failure in Candida albicans endophthalmitis. Clin Infect Dis. 2005;41(3):e27-e28.

168. Goldblum D, Fausch K, Frueh BE, Theurillat R, Thormann W, Zimmerli S. Ocular penetration of caspofungin in a rabbit uveitis model. Graefes Arch Clin Exp Ophthalmol. 2007;245(6):825-833.

169. Kernt M, Hirneiss C, Neubauer AS, et al. Intracameral moxifloxacin: A safe option for endophthalmitis prophylaxis? In vitro safety profile for intraocular application. Ophthalmologe. Epub ahead of print 2009 sep 17.

170. Espinel-Ingroff A. Comparison of in vitro activities of the new triazole SCH56592 and the echinocandins MK-0991 (L-743,872) and LY303366 against opportunistic filamentous and dimorphic fungi and yeasts. J Clin Microbiol. 1998;36(10):2950-2956.

171. Klepser ME, Ernst EJ, Ernst ME, Messer SA, Pfaller MA. Evaluation of endpoints for antifungal susceptibility determinations with LY303366. Antimicrob Agents Chemother. 1998;42(6): 1387-1391.

172. Pfaller MA, Marco F, Messer SA, Jones RN. In vitro activity of two echinocandin derivatives, LY303366 and MK-0991 (L-743,792), against clinical isolates of Aspergillus, Fusarium, Rhizopus, and other filamentous fungi. Diagn Microbiol Infect Dis. 1998;30(4): $251-255$.

PubMed Central and CAS, and is the official journal of The Society of Clinical Ophthalmology (SCO). The manuscript management system is completely online and includes a very quick and fair peer-review system, which is all easy to use. Visit http://www.dovepress.com/ testimonials.php to read real quotes from published authors. 